tinued, and I ordered s small portion of the following ointment to be rubbed in over the seat of pain, night and marning.

R. Unguenti hydrargyri fortioris, unguenti camphoræ, āā ̧̧ss; extracti belladonne gr. iv. Fiat unguentum.

June 6th. (Her sister was married on this day.) She had a violent hysterical attack, which gare way to the usual remedies, quiet and opium. Pulse 96 ; rather better in character, but still feeble. The ointment was ordered to be continued.

June 9th. Pain diminished; she was able to sit in a chair comfortably for the first time.

June 13th. She had a slight hysterical attack for half an hour, which subsided without medical interference.

June 20th. The abdominal pain had materially abated, indeed was not perceptible, except on pressure over the part. Her appetite had been failing for the last two or three days, and she complained of a feeling of heat at the stomach. Continue the ointment.

R Potassa bicarb. $3 \mathrm{ij}$; acidi citrici 3 iss; acidi hydrocyanici diluti $m \times$ ij ; aquæe destillatæ ad $\bar{\jmath}^{\mathrm{vj}}$. Fiat mist. Capiat zj ter quotidie.

June 30th. She was now entirely free from pain; her general health improved; appetite good, and she had no bad symptom of any kind. She had no return of hysteria since the 13th.

ReMarkg. The above case presents no features opposed to the views which I advanced in my last paper concerning the etiology of hysteria, that a peculiar condition of the nerrous system is a predisposing cause, and that the ovarian lesion is very frequently an exciting cause. This patient had never observed any irregularity in the ovariouterine system, and she.had not been habitually liable to hysteria. She had once had an attack of this nature, and it is not unreasonable to suppose that, synchronous with this, at the age of puberty, or soon after, there may have been some slight disorder of the generative system, which had escaped her notice. On the present occasion, we find her suffering from both ailments, and the one disappearing simultaneously with the other. The immediate cause of the ovarian inflammation remains a question. It was not improbably owing either directly to the accident before mentioned, or indirectly to the enteric affection in the neighbourhood. Though the ovarian lesion had probably existed for several weeks, hysterical symptoms did not take place until the marriage of her sister, which, occasioning her considerable excitement, disturbed the whole nervous system. As regards the treatment of such cases, I have found leeches, and the milder preparations of mercury, to be among the most efficacious, and the use of the latter is seldom required to be pushed so far as to affect the gums. In this case, leeches were not applied, as there had been a sufficient drain upon the circulating system at the time of the confinement. The sanguineous and nervous systems were well balanced; but if there was any tendency to an abnormal state, it would be to the hyperæmic condition.

\section{CASES OF LITHOTONY.}

By Winumar Thorras Benc, Esq., Great Grimsby.

Case I. Lithotomy: Rapid Recovery. Charles Pearson, aged 5 years, a widow's son, of fair complexion, light hair blue eyes, and healthy appearance, came under my care in November 1855. He had suffered for twelve months from symptoms of stone, varying in intensity, with occasional difficulty in passing urine, and roiding it more frequently than natural, with pain at the end of the penis, which caused him to pull the prepuce. When passing his urine, he would have a desire to go to stool at the same time, producing prolapsus ani. During the last two months, his symptoms had kept increasing; he could not hold his water for long at a time. His urine was clear, and he passed no blood. His general health was very good. A sound was introduced into the bladder, but I could not de- tect stone. He kicked about much; and the bladder would not tolerate any water to be injected. $\Delta$ fer days afterwards, under chloroform, I sounded him a second time, and readily felt one. As his mother was not in a good stato of health, the operation was postponed for a time. In this interval, he took carbonate of soda and tincture of henbane, with mucilage; and kept his bowels open with castor oil.

January 13th, 1856. Under chloroform, I performed the lateral operation of lithotoiny. There was no bleeding. The calculus was of about the size of a bean, long and soft, and would scarcely bear the forceps. Afterwards an opiate was given. During the night, he passed his urine by the urethra, and freely by the wound. At night, another opiate was given.

Jan. 14th. He slept well during the night; urine continued to pass as above. There was slight fever. I ordered a saline draught every four hours; and a powder, with calonel and Dover's powder, at bedtime.

Jan. 15th. Doing very well.

Jan. 16th. The bowels were not moved. I ordered a dose of castor oil. Urine passed freely by the urethra, and very little through the wound. The saline was continued.

Jan. 17th. Going on very well. I ordered him a better diet, and to leave off the saline.

In three wecks time he was perfectly cured.

CASE II. Lithotomy. James Lingard, aged 63 years, labourer, of short stature, much care-worn, came under my care in July 1855, with stune in the bladder. He had always enjoyed good health up to three years ago.

Uistory of Disease. Thirty years ago, he passed a quantity of lithic acid sand; and three years ago he passed two small calculi without much difficulty; and ever since this had been getting worse, and for the last year had been incapacitated from work.

The symptoms were those usual to stone in the bladder. There was a considerable deposit of mucus in the urine upon standing. I sounded him, and found a stone of large size, measuring $14^{\circ}$ of Ferguson's lithotrite. There was considerable enlargement of the prostate gland. He was anxious to have the stone crushed; but, taking into consideration the irritability of the patient, the hardness of the stone, and the enlargement of the prostate gland, with an assurance that he would not kecp in bed for any length of time, I detcrmined to perform the lateral operation of lithotomy.

July 2nd. Under chloroform, I performed lithotomy. The operation lasted $t w 0$ and a half minutes. There was rather free hæmorrhage at the time from the transverse artery of the perinæum and the reins of the prostate. To arrest this, I plugged the wound with sponge, and put an elastic catheter into the bladder; brought the knees together, and gave an opiate.

The after treatment consisted in low dict for a few days, with salines; then a good generous diet, with porter, and tobacco to smoke ad libituin. He made a good recovery, and walked to my surgery, a distance of a hundred yards, three days within the month after the operation, although the wound was not quite healed. In a few days after this, he went home, a distance of eight miles; and I lost sight of him for a time. Some time after the operation, a small fistulous opening remained in the perinæum, but he refused to have anything done for its relief.

The calculus was flat, and of the circumference of a full sized walnut, composed of distinct laminæ, and very hard.

\section{CASE OF PLURAL BIRTH.}

By R. Coker N. Davies, Esq., Rye, Sussex.

Or the morning of December 14th, 1855, I was summoned to the union house, to attend - M., aged 19 years, single. On arrival, I found her to be in labour. The membranes had broken, and a head presented. The child was soon born; and after waiting a little time, and making 
acoond examination, I detected another bag of membranes, and a second head presentation. On rupturing this bas, a second child was speedily born. On exploring the abdomen with $m y$ hand, I could detect another foetus in utero; consequently, I again made an examination per vaginam, and then discovered another bag of membranes entire, and transverse presentation. I then ruptured the membranes a second time, and turned the child. Thero was but one placenta, and that not an unusually large one.

After a short labour of a few hours. the woman was safely delivered of three full grown male children. One lived twelve hours; another, twenty-four; and the last survived three days. This was the woman's first confinement.

\section{ON THE MURMURS OF THE HEART AND GREAT VESSELS.}

By R. Hotchixson Poweln, M.D.Lond., Physician to the Royal Infirmary for Diseases of the Chest.

[Coucluded from page 107.]

Trn preceding statements show, at all events, that we have still to discuss the first principles of cardiac action, and preclude mere dogmatising, as opposed to observation. If it be $a$ fact that the impulse of the heart and the arterial pulse are not iso-chronous, even allowing for the fractional moment consumed in overcoming vascular elasticity, also for the retarding effect of regurgitant disease, it will be necessary to re-state and re-arrange the respective movements and sounds as regards diagnosis. Thus, in obstructive valvular (mitral) disease, cardiac murmur will not coincide with ventricular contraction, but with dilatation and impulse. The relation held to exist between impulse, first sound, systole, and pulse, becomes necessarily disjointed; the two former phenomena being first, the two latter next, and the second sound last, in order. As regards the causation of the heart's sounds, any person may convince oneself of their very simple character-being rather tactile shocks, perceptible to the ear, than true acoustic soundsby tapping the palm when covering the ear, which very closely simulates them, especially the first sound. Much of the obscurity in question may be ultimately cleared up by attending to circumstances connected with cardiac phenomena, when disease results in the walls, orifices, or valves of the heart. This leads us to advert to the mode of production of cardiac murmurs, and I may here call attention to the close correspondence, if not agreement, existing between the opinions broached by Dr. Corrigan and the deductions of Professor Kiwisch. A quotation from Volkmann will again assist us.

It will be observed that the pressure is regulated by proximity to, or distance from the heart, also by the diameter of the tube, and determinate friction of the contained fluid. The undulatory movement in the vessels somewhat resembles that described by Skoda in the exposed infant's heart. It follows, moreover, that the proclivity to the production of murmurs in the circulatory system is influenced in a corresponding degree, as below referred to.

"The laws regulating the movement of the blood, in the living organism, are identical with those determining the movement of fluids in artificial tubes; the logical element being the same in both. The lateral pressure results from the adhesion and friction occurring between the liquid and the parietes of the tubes. This lateral pressure, at any one point of the tube, being proportional to the resistance to be overcome by the movement of the water (or other fluid) at this point.

"The lateral pressure, exerted at different points of a tube of uniform dimensions, is inversely as their distance from the discharging orifice; the ratio of the length of the tube to the lateral pressure appears constant; but the lateral pressure is almost inversely as the diameter of the tube: yet this pressure increases as the width diminishes, the pressure not being uniform throughout the arterial system, as asserted by Poisseuille.
"The pressure of the blood is subject to a gradual diminution from the commencement of the arterial to the termination of the venous system; points equidistant from the centre of motion, suffer varying degrees of pressure, which is increased in parts through which the blood passes with difficulty; the capillaries, occupying an intermediate position, suffer over half the maximum near the heart.

"To distension of a tube, caused by intermittent injections, succeeds contraction, dependent upon its elasticity both movements do not take place simultaneously throughout, but by undulations from one end to the other; this wave-like motion being essential to the formation of a current.

"The blood pressure is equal to one quarter of that of the atmosphere, varying with the distance of the tubes (arterial, capillary, or venous) from the point of departure, and with the species of animals; the variation ranging from a third to an integral number in mammals.

"Warm-blooded animals possess a greater arterial pressure than the cold-blooded, being lowest in carly and advanced, and highest in the prime of life, and not being in proportion to the size of the animal.

"The velocity of the blood-current (as distinguished from the space traversed by a blood particle in a given time) is considerably greater in the arteries than that in the capillaries; being at a maximum in those in propinquity with the heart, but not being identical in the analogous vessels of different animals, yet not varying more than in animals of the same species; the mean relocity in the carotids of mammals being about twelve inches per second."

I next subjoin a resumé of Kiwisch's deductions; which, though not devoid of some obscurity and apparent contradiction, are rery valuable, and closely applicable to the subject in hand.

"Elastic membranes in the vessels give tone or murmur under two conditions; either when thrown into ribration by an external influx (tone), or being relaxed, are suddenly made tense (murmur). The motion of the blood in the vessels of itself never gives rise to sound; sounds heard in them entirely resulting from the movements of their walls, produced by the fluid in motion. Sounds pass into murmurs from unequal tension and irregular vibrations. In a vessel of unequal calibre, vibrations and sounds arise, which are either tones or murmurs, according to their rapidity. The blood-current preserves its shape when passing into a wider space and less tense tube; the elasticity of the tube causes contraction, then expansion, and again contraction; and thus successive movements, if sufficiently rapid, produce sound, its kind depending upon the parietal thickness, width, and form of the column, and not being produced in the narrow, but wider succeeding point.

"All vascular bruits are pre-eminently occasioned", $\mathrm{Dr}$. Kiwisch states categorically, "by the inequality of space in the bore of the ressel, and by the unequal tension of the latter. A determinate acceleration of the sanguineous current, and a relative peripheral diminution of the blood column, are conditions more remotely concerned in their production.

"The inequality of space is produced most frequently by a partial compression of the arteries, more rarely by the augmentation of their diameter.

"The vascular bruits observed in chlorotic subjects, like those heard in the abdomen during pregnancy, are mark edly phenomena of compression.

"Bruits are never produced in the veins, but are invariably to be sought for in the arteries.

"According to this view, there exists, then, in the arteries, continuous murmurs, that is to say, systolic and diastolic sounds are therein produced."

[Many of the above deductions, it will be remarked, differ from the views previously held as to venous and placental murmurs, and require confirmation.]

"In the vascular parietes, during health (?), diminution of the muscular contraction in the vessels, and imporerished blood, are the chief elements giving rise to vassular murmurs. 